\title{
Assessing the Strategic Fit of Potential M\&As in Chinese Banking: A Novel Bayesian Stochastic Frontier Approach ${ }^{1}$
}

\begin{abstract}
Banking in China is well-known for being extremely fragmented, thus making the analysis of the sector a not straightforward task. This research aims to explore the strategic fit of potential mergers and acquisitions in the Chinese banking industry. When the operations of two banks are jointly analyzed this means that the inputs and the outputs of these two individual banks are somehow combined in an attempt to better understand the sector as a whole. A novel SFA model with Bayesian inference on input/output prices is proposed to assess the impact of business-related variables on efficiency levels. The results not only reveal that bank size, type, and origin present a significant impact on individual technical efficiency levels, but also exert a significant impact on the efficiency frontier of the industry. The strategic fit of M\&A in the Chinese banking industry strongly relies on opportunities derived from banking automation that may arise from acquiring technologically obsolete small banks. Big and foreign banks also exert a positive impact on the technological catch-up of Chinese banks, which may suggest opportunities for sector deregulation.
\end{abstract}

\section{JEL Classification: C6, G21, G34}

Keywords: Banks; China; Potential merger and acquisitions; SFA; Bayesian inference; strategic fit.

\section{Introduction}

The term mergers and acquisitions (M\&A) refers to the process of merging or acquiring all or part of another company's property rights. An M\&A is carried out under certain conditions to obtain controlling rights (Song and Chu, 2006). A merger or acquisition is an important strategic move made by a company to improve its enterprise performance management. Successful mergers can produce many gains such as cost savings, increased profits, upscaling, and freeing up abundant resources (Johnes and $\mathrm{Yu}$, 2008; Fried et al., 1999; Weber and Dholakia, 2000; Halkos and Tzeremes, 2013; Peyrache, 2013). In the banking sector, for example, Chase Manhattan Bank and Hurray Bank merged

\footnotetext{
${ }^{1}$ The authors would like to thank the editor and the two anonymous referees their helpful comments in improving this paper.
} 
in 1995 with the purpose of cutting operational cost as the two banks were near in geography and similar in operating business. After the merger, the merged bank saved US $\$ 1.5$ billion in expenses, as a result of shutting down overlapped branches and laying off staff among other factors. Afterwards, Chase Manhattan acquired Hambrecht \& Quist in 1999, and Robert Fleming and Beacom in 2000 for the same input-saving purpose.

As a matter of fact, banks are seeking optimal positioning of their activities in the market for converging to an optimal size. This explains their recourse to M\&A to converge to that size. In this context, Chaffai and Dietsch (1999a) noted that M\&A enables banks to reduce their costs and improve their efficiencies at the allocative and productive levels. Indeed, according to the industrial economy theory, it is often assumed that size is strongly linked to economies of scale. Actually, a size increase involves a lower unit cost due to the decrease in the mean fixed cost. In fact, according to Chaffai (1998), Chaffai and Dietsch (1999a), Chaffai and Dietsch (1999b), and Sassenou (1992), there exists only one critical size that can minimize the unit production costs.

Another aspect that impacts on the optimal size of the banking industry is related to the emergence of increased banking automation as a consequence of the IT revolution. Cost savings derived from large scale IT adoption in banking operations has positively contributed to the profitability of this industry by means of services scalability (Ho and Mallick, 2010). The effects of the IT revolution on the banking activity in terms of services scalability and, therefore, on the optimal scale size, had a clear implication on diminishing the competitive power of technologically obsolete small banks. This opened room for diverse forms of restructuration of the banking industry, which may range from network collaboration and joint ventures (Ho and Mallick, 2010) to M\&As.

Specifically, with respect to M\&As, there has been a growing number of studies examining the potential gains to be made from mergers in the bank sector based on the strategic fit of two banks (Shi, Yongjun, Emrouznejad, Xie, \& Liang, in press; Gattoufi, Amin, \& Emrouznejad, 2014). The underlying idea is that, in order to decrease the high failure rate of M\&A activities, a bidder bank should try to identify suitable target banks prior to an M\&A is to determine whether the prospective partner can offer synergies and the necessary relevant attributes to complement their operations (Wanke et al., 2017, 2016). The need to predict M\&A outcomes has drawn the attention of many researchers (Dietrich and Sorensen, 1984; Pasiouras and Gaganis, 2007; Powell, 2001; Gale and Shapley, 1962), including those focused on efficiency measurement (Chow and Fung, 2012). As regards efficiency measurement, this is often done by assessing the impact of contextual, businessrelated, variables of the bidder and target banks in terms of the individual efficiency levels of the potential merged banks and their impacts upon the efficiency frontier (Wanke et al., 2017, 2016).

This research focuses on the strategic fit of potential M\&As involving Chinese 
banks, taken two-by-two, by using a novel stochastic frontier model capable of simultaneously controlling the impact of contextual variables - of bidder and target banks - on the resultant technical change of the sector (frontier shift effect), productive change of the sector (catch-up effect), and on individual efficiency levels of the potentially merged banks.

As a distinctive feature of the proposed stochastic frontier model is the use of a Bayesian approach for inferring how input and output capital and labor prices may vary after merging two individual banks. Most previous SFA (Stochastic Frontier Analysis) studies in banking have not only neglected the analysis of the impact of potential mergers on this sector (Kraft and Tirtıroğlu, 1998; Kohers et al., 2000; Okeahalam, 2006; Baten and Kamil, 2011; Sun and Chang, 2011; Tabak et al., 2013; Mamatzakis et al., 2015), but also failed short in a more systematic research approach to M\&As in China (Fu and Heffernan, 2007, 2009; Berger et al., 2009; Fungáčová et al., 2013; Jiang et al., 2009, 2013; Sun et al., 2013; Yin et al., 2013; Dong et al., 2014; Hsiao et al., 2015; Silva et al., 2017). These two aspects suggest a literature gap to be filled.

The relevance of this study also relies on the uniqueness of the Chinese banking industry, which is singular for several reasons. First, it is one of the largest and most sophisticated in Asia. More and more, Chinese banks rank in the Top 1000 world banks in the list of The Banker. According to the statistics of Financial Times, the total assets of the Chinese banking industry, excluding the shadow banks, has amounted to US\$ 33 trillion by the end of 2016. Meanwhile, commercial banks have played a much more important role in the financial system of China, similar to the case in Japan and Germany. Second, Chinese commercial banks have continually experienced different waves of reforms when the economy of China began to implement the "open-up and reform" policy since 1978. More importantly, during the recent turn of reform after 2001 when China became part of the World Trade Organization (WTO), M\&A has been one of most significant aspects when these banks started to improve the governance and enhance their competitiveness through joint-stock reform (Barros et al., 2011; Pessarossi and Weill, 2015). Lastly, to our best knowledge, in the expected future, M\&A will still be one of development themes for the banking system as dozens of banks have been established in recent decades (FernándezArias et al., 2017). The outbreak of a global financial crisis and the flourishing of internet Finance have also driven some banks to the edge of bankruptcy. This research and its policy implication will help the future reform to further improve the development of Chinese banks.

Therefore, the motivations for the present research are as follows. Firstly, although the last wave of financial reform has given rise to M\&A events in the bank industry of China, there is nearly no research that has paid attention to this issue. It is time for us to investigate whether the M\&A of Chinese banks can lead to better performance. Secondly, 
most of the studies on bank M\&As have used the "efficiency hypothesis", which is based on the realization of economies of scale and other efficiency gains in the merged bank (Craig and Dinger, 2009; Halkos and Tzeremes, 2013; Du and Sim, 2016). However, some other researchers provide exactly opposite results for some other countries (DeLong and DeYoung, 2007; Du and Sim, 2016). It is worth examining China's specific situation.

This paper is structured beginning with this introduction and then presents the contextual setting, which includes a description of the Chinese banks. The literature survey is then presented followed by the methodology section in which the novel SFA model is presented. Section 5 presents the data and discusses the results. Conclusions are given in Sections 6.

\section{Contextual Setting}

With the rapid development of Chinese banks, M\&As have always dominated the reform and structure change. Before 1978, the People's Bank of China (PBC) ${ }^{2}$, which was set up by merging existing banks in 1949, functioned as a central bank as well as a commercial bank. In other words, it was characterized as a mono-bank (Barros et al., 2011). Later when China switched from a central-planned economy to a market-oriented economy, the government authorities decided to reestablish or establish four specialized banks (SBs), which are the Agricultural Bank of China (ABC), the Bank of China (BOC), the China Construction Bank $(\mathrm{CCB})^{3}$ and the Industrial and Commercial Bank of China (ICBC). All these banks came out of the PBC except for the CCB, which came from the Ministry of Finance, and operated respectively in the agricultural area, the foreign exchange area, the fixed assets investment area, and the industrial and commercial area.

With the reform accelerated, the government started another wave of restructuring. For example, in 1994, the government founded three policy banks ${ }^{4}$ to take over the policyrelated business from the four SBs in order to transform the latter into commercial banks, which are characterized as market-functioning modern companies for profit (Barros et al., 2011; Pessarossi and Weill, 2015). After the Asian Crisis, four asset management companies (AMC) were established by the government to strip off many bad loans from the four SBs. Since 1986, the authorities have successively approved the founding of several joint-equity commercial banks, including national joint-equity commercial banks

\footnotetext{
${ }^{2}$ The PBC was not separated from the Ministry of Finance of China until 1978.

${ }^{3}$ The Bank of China was originally set up in 1905, the Agricultural Bank of China in 1951, and the China Construction Bank in 1954.

${ }^{4}$ I.e., the China Development Bank, the Export-Import Bank of China, and the Agricultural Development Bank of China.
} 
as well as regional commercial banks ${ }^{5}$, so as to decrease the monopoly power of the four SBs in the financial market.

In the last two stages of the reform, the M\&As and restructuring were controlled and manipulated by the government. When the Chinese commercial banks had more autonomy power as modern companies, more M\&A events began to take place driven by the market, especially after 2005 when preparing to launch the IPO (initial public offer) on the stock market as a public limited company. Most of the SBs and national joint-equity commercial banks had tried to attract notable foreign commercial banks or financial institutions as strategic investors so as to ameliorate the internal governance or advance their technology and management practices. The first M\&As with foreign banks took place in 2001 when the Hong Kong and Shanghai Banking Corporation Limited (HSBC) acquired $8 \%$ of Shanghai Bank. Thereafter, the foreign financial companies began to pour into Chinese market and try to find potential targets of M\&As. The Chinese government forbids a foreign company to be the major shareholder of two similar domestic banks. In the middle of 2015, the CBRC began to promulgate new regulations on M\&As by these foreign investors, such as the percentage of a domestic bank's share held by a single foreign investor cannot exceed 20, while the percentage of a domestic bank's share held by the entire foreign investors cannot exceed 25.

After the global financial crisis in 2008, some giant domestic banks such as ICBC have started outbound M\&As, but these cross-border targets are always small banks that are in trouble due to the crisis. At this stage, M\&As between domestic banks are quite limited, but its volume may increase in the future.

\section{Literature Review}

Most of the benchmarking literature is concerned with evaluating the performance of individual banks (Alba et al., 2009; Silva et al., 2015). It is, however, also possible to evaluate the efficiency of a group of banks and thus to evaluate whether the best possible industry structure would imply the merger of some of these banks. This is the underlying idea beneath the strategic fit of merger and acquisitions, in terms of unveiling the drivers or contextual variables of the most adequate banking industry organization. Putting it into other words, the underlying idea is to assess how different business characteristics of bidders and targets may eventually improve technical efficiency levels as well as the efficiency frontier, as long as, banks are systematically chasing the best possible size, market positioning, and resource allocation. Putting it on other way around, however, there

\footnotetext{
${ }^{5}$ According to statistics from the China Banking Regulatory Commission (CBRC), there were 5 state-owned commercial banks, 12 joint-equity commercial banks, and 133 city commercial banks by the end of 2015 .
} 
may also be a particular set of business characteristics were M\&As are no beneficial in terms of efficiency levels and efficiency frontier for the banking industry.

Besides, it is interesting to note that there is considerable debate on the necessary time elapsed for efficiency gains to fructify on actual M\&As that took place in practice. The appropriate timescale for evaluating the resulting actual merger performance, either in terms of technical efficiency gains or in terms of profit generation, is still a question to be answered. Very often, the technical efficiency impact of M\&As needs a sufficient longterm before evaluating, because efficiency improvement occurs over a long time horizon (Manson et al., 2000; Ghosh, 2001; Rahman and Limmack, 2004). On the other hand, as regards profit generation, a longer time scale creates different problems like higher chances of other operational or financial policy impacts on the bank valuation (Sudarsanam, 2010). Nevertheless - and keeping it in mind that there are banking studies focused on the strategic fit of mergers and others on actual mergers - the perception that the M\&As of banks can lead to improved banking performance has a strong intuitive appeal.

Therefore, studies analyzing the efficiency gains of M\&A in the banking industry have been conducted recently and form a particular strand of literature (Halkos and Tzeremes, 2013). For example, Bogetoft and Wang (2005) built economic production models and used them to estimate the potential efficiency gains from mergers. Kohers et al. (2000), Beccalli and Frantz (2009), and Lozano and Villa (2011) also estimated the efficiency gains resulting from a merger. Using data from six emerging countries, Du and Sim (2016) found that target banks tended to be more efficient after an M\&A, but no efficiency improvements were found for bidder banks, thus indicating the importance to separate target from bidder banks.

However, studies on M\&A in banking are still in progress and the existing ones had failed to provide a common understanding about the relationship between bank M\&As and performance, since their results are conflicting due to the abovementioned reasons (Amel et al., 2004; Halkos and Tzeremes, 2013). It is worth mentioning that a number of different alternative approaches have been applied (Halkos and Tzeremes, 2013; Peyrache, 2013; Lo et al., 2001; Liu et al., 2007). There are, for instance, empirical studies that show that efficiency gains do not coincide with return to scale nor produce overall benefits for the industry in terms of frontier shift and catch-up effects (Chapin and Schmidt, 1999; Harris et al., 2000). In fact, banks are particularly looking for the optimal positioning of their activities on the market and for converging to an optimal size, regardless of the impacts of their decision on the industry as a whole. Therefore, when assessing the strategic fit of M\&As, one should focus not only on efficiency gains at the bank level, but also on the creation of an oversized resulting bank or on an stagnant situation as regards technical and productive changes for the whole industry. 
Moreover, despite M\&A activities being plentiful in China, the academic research has paid no attention to them. There is also a large strand of literature on the research of efficiency of Chinese banks using different models, including DEA (Data Envelopment Analysis) and SFA (Barros et al., 2011; Toloo et al., 2015), but they have not linked it with M\&As, especially with respect to the stochastic parametric models. In this respect, this paper is innovative by using an updated and comprehensive dataset of Chinese banks and by adopting a novel SFA model to assess the strategic fit of M\&A on the technical and productive changes, as well as on efficiency levels. This model is further discussed in Section 4 and its subsections.

\section{The novel stochastic model for M\&A}

This section describe the novel stochastic frontier model developed for assessing the impact of potential mergers in the Chinese banking industry. Before proceeding, it is

worth clarifying its distinctive features from previous models: (i) the weight vector $\alpha$, that allows inputs and outputs of merged banks to vary in different proportions (cf. Eq. (5); (ii) the modelling of the stochastic frontier under the cost minimization and profit maximization frameworks (cf. sections 4.1 and 4.2) allowing for an unbalanced data panel specification; (iii) the Bayesian statistical inference on the possibly newer technology of the potentially merged banks (cf. sections 4.3 and 4.4) based on Markov-Chain MonteCarlo approach; and (iv) the decomposition of the error terms with respect to a vector of contextual variables (cf. Eq. 17). Another distinctive aspect of the proposed model is that the input/output prices of the potentially merged banks are also statistically inferred (cf. section 4.3. for further details).

Suppose $x \in \mathbb{R}_{+}^{K}$ is a vector of inputs whose prices are $w \in \mathbb{R}_{+}^{K}$ and $y \in \mathbb{R}_{+}^{M}$ is a vector of outputs whose prices are $p \in \mathbb{R}_{+}^{K}$. Suppose we focus on cost minimization problem:

$$
C(w, y)=\min _{x \in \mathbb{R}_{+}^{K}}: w^{\prime} x, \text { s.t. } F(x, y)=1,
$$

where $F(x, y)$ is a transformation function which we can take without loss of generality as an output-distance function. Optimal input demand functions can be obtained via Shephard's lemma:

$$
x_{k}(w, y)=\frac{\partial C(w, y)}{\partial w_{k}}, k=1, \ldots, K
$$


In share-equation form we have the equivalent expression:

$$
s_{k}(w, y) \equiv \frac{w_{k} x_{k}}{\sum_{k^{\prime}=1}^{K} w_{k^{\prime}} x_{k^{\prime}}}=\frac{\partial \ln C(w, y)}{\partial \ln w_{k}}, k=1, \ldots, K
$$

The problem we are facing is as follows. Suppose we have two decision-making units, say $d$ and $d^{\prime}$, and we wish to examine the appropriateness of a merger. The inputs and outputs of the DMUs are $x_{d}, y_{d}$ and $x_{d^{\prime}}, y_{d^{\prime}}$. As the merger is only hypothetical, we do not have direct evidence to evaluate it, but we wish to make an informed statement about the merging decision. After the merger, the inputs and outputs of the joint firm are assumed to be $x^{*}, y^{*}$ and prices remain the same, mostly for simplicity in presentation.

If we adopt the profit-maximization approach, then we can define the profit function:

$$
\Pi p, w=\max _{x \in \mathbb{R}_{+}^{K}, y \in \mathbb{R}_{+}^{M}}: p^{\prime} y-w^{\prime} x \text {, s.t. } F(x, y)=1 \text {. }
$$

Hotelling's lemma can be used to obtain the input demand and output supply functions. This framework is, we believe, also convenient for examining mergers. The reason is that input and output prices are likely to be the same after the merger and only the input demand and output supply functions of the new firm will change. In which direction they will change can be handled using the techniques we describe below.

Whether the technology is the same or not is not a concern at this stage, as we will show later in the paper how we can account for possible differences in technology. A reasonable assumption about the inputs and outputs of the new firm is the following:

$$
\begin{aligned}
& x_{k}^{*}=\alpha_{k}^{x} \quad x_{k, d}+x_{k, d^{\prime}}, k=1, \ldots, K, \\
& y_{m}^{*}=\alpha_{m}^{y} y_{m, d}+y_{m, d^{\prime}}, m=1, \ldots, M .
\end{aligned}
$$

In these expressions, when $\alpha_{k}^{x}=\alpha_{m}^{y}=1$, then the inputs and outputs of the new firm are simply the sums of inputs and outputs for the two firms. When these coefficients are less (greater) than one, it means that inputs or outputs of the new firm are reduced (increased). Notice that the coefficients i) must be positive, ii) they can be less or greater than one and, and more importantly iii) they are allowed to be different for each input and each output. This brings up the following questions: a) how these coefficients are determined and $b$ ) how the new firm is defined. 
Regarding (b), if the technology described by the cost function is the same, the vectors $x^{*}, y^{*}$ unambiguously define the new firm. We will proceed under this assumption, but we will remove it in the next section. As regards the strong assumption on prices, it is also removed. Readers should note that the inference procedure further described in Section 4.3, allows prices to be re-estimated each time a potential merged is computed, as long as there $n-1$ banks left in the system. In fact, Eq (13) is re-estimated along with the vector $\alpha$ in (5), which is used to aggregate the inputs and outputs. Eq. (14) is also re-estimated.

\subsection{Cost minimization framework}

Suppose we have observations $x_{i t}, y_{i t}, w_{i t} \in \mathbb{R}^{2 K+M}$ for DMUs $i=1, \ldots, n$ and time periods $t=1, \ldots, T$. We abstract from the issue of unbalanced panels as the issue can be dealt with easily. First, we can estimate the standard cost-share system:

$$
\begin{aligned}
& \ln C_{i t}=f \ln w_{i t}, \ln y_{i t} ; \beta+v_{i t, 1}+u_{i t}, \\
& s_{k, i t}=g_{k} \ln w_{i t}, \ln y_{i t} ; \beta+v_{i t, k}, k=1, \ldots, K-1, \\
& i=1, \ldots, n, t=1, \ldots, T .
\end{aligned}
$$

where $v_{i t, 1}$ and $v_{i t, k}$ are error terms, $u_{i t} \geq 0$ represents technical inefficiency, $f \ln w_{i t}, \ln y_{i t} ; \beta$ is a translog functional form for the cost function depending on a parameter vector $\beta \in B \subset \mathbb{R}^{p}$ and

$$
g_{k} \ln w_{i t}, \ln y_{i t} ; \beta=\frac{\partial f \ln w_{i t}, \ln y_{i t} ; \beta}{\partial \ln w_{k, i t}}, k=1, \ldots, K-1 .
$$

We omit the last share equation as usual. For the error terms, we assume

$$
v_{i t}=\left[v_{i t, 1}, v_{i t, 2}, \ldots, v_{i t, K-1}\right]^{\prime} \sim N_{K} 0, \Sigma, i=1, \ldots, n, t=1, \ldots, T
$$

where $\Sigma$ is a covariance matrix. After estimation of the cost-share system, we obtain estimates $\hat{\beta}$ of $\beta$ and estimates of technical inefficiency. Suppose now we combine units $d, d^{\prime}$ using (5) and a new observation is created. Apparently, we now have $n-1$ observations. The system in (6) can be re-estimated and a new parameter vector $\hat{\beta}^{*}$ and 
new estimates of technical inefficiency are obtained, say $\hat{u}_{i t}^{*}$, returns to scale, technical change, etc. In this way, we can compare $\hat{u}_{i t}^{*}$ to inefficiencies of DMUs before the merger. We can do the same comparison using technical change and total cost $f \ln w_{i t}^{*}(\alpha), \ln y_{i t}^{*}(\alpha) ; \hat{\beta}^{*}$ where $\alpha$ is the vector of unknown coefficients in (5). As this vector of coefficients is unknown, it must also be estimated so that we obtain an objective way to aggregate inputs and outputs of the new firm.

\subsection{Profit maximization framework}

In the profit-function framework we adopt the following profit function of the form

$$
\begin{aligned}
& \ln \Pi_{i t}=f_{\Pi} \ln w_{i t}, \ln p_{i t}, \beta_{\Pi}+v_{i t, 1}-u_{i t}, \\
& \frac{w_{k, i t} x_{k, i t}}{\Pi_{i t}}=g_{k, \Pi} \ln w_{i t}, \ln p_{i t}, \beta_{\Pi}+v_{i t, k}, k=1, \ldots, K, \\
& \frac{p_{m, i t} y_{m, i t}}{\Pi_{i t}}=g_{m, \Pi} \ln w_{i t}, \ln p_{i t}, \beta_{\Pi}+v_{i t, K+m}, m=1, \ldots, M,
\end{aligned}
$$

where, by Hotelling's lemma:

$$
\begin{aligned}
& x_{k} p, w=-\frac{\partial \Pi p, w}{\partial w_{k}}, k=1, \ldots, K, \\
& y_{m} p, w=\frac{\partial \Pi p, w}{\partial p_{m}}, m=1, \ldots, M,
\end{aligned}
$$

which can be converted easily to elasticity form:

$$
\begin{aligned}
& g_{k, \Pi} \ln w_{i t}, \ln p_{i t}, \beta_{\Pi}=-\frac{\partial \ln \Pi_{i t} \ln w_{i t}, \ln p_{i t}, \beta_{\Pi}}{\partial \ln w_{k, i t}}, k=1, \ldots, K, \\
& g_{m, \Pi} \ln w_{i t}, \ln p_{i t}, \beta_{\Pi}=\frac{\partial \ln \Pi_{i t} \ln w_{i t}, \ln p_{i t}, \beta_{\Pi}}{\partial \ln p_{m, i t}}, m=1, \ldots, M .
\end{aligned}
$$

We can make similar distributional assumptions as in the cost-minimization case, viz:

$$
v_{i t}=\left[v_{i t, 1}, \ldots, v_{i t, K+M+1}\right] \sim N_{K+M+1} O, \Sigma, i=1, \ldots, n, t=1, \ldots, T
$$


and obtain parameter estimates, say $\hat{\beta}_{\Pi}$ and estimates of technical inefficiency, say $\hat{u}_{i t}$, technical change, returns to scale, estimated $\log$ profits, $f_{\Pi} \ln w_{i t}, \ln p_{i t}, \hat{\beta}_{\Pi}$, etc.

After a merger where prices remain the same, the only change is the optimal input demand and output supply functions are different when two DMUs are merged. To merge them we need to define profit and inputs and outputs observed, which can be done as in (5). In this case, the entire profit system will depend on the weight vector $\alpha$, which must be, again, estimated. A crucial point is that some prices are often defined depending on inputs or outputs, such as total personnel expenses divided by number of employees. In this case, both personnel expenses and number of employees need to be combined for the new firm. Although the most obvious solution is to add the respective variables for the two DMUs, this may not be the case with other prices such as price of deposits, loans, etc. in the case of banking. Therefore, formal estimation of $\alpha$ is needed in such cases. Since we usually have a pretty good idea of what the weights should have been, we can adopt a Bayesian approach, which allows us to place specific priors on $\alpha$.

\subsection{DMU-specific technologies}

In this section, we address the issue of different technologies for different DMUs (Decision Making Units). Here the problem becomes more difficult because the technology of the merged firm will also be different in an unknown way. As the issues are the same in cost minimization and profit maximization, we consider only the former case and we rewrite (6) in the following form:

$$
\begin{aligned}
& \ln C_{i t}=f \ln w_{i t}, \ln y_{i t} ; \beta_{i}+v_{i t, 1}+u_{i t}, \\
& s_{k, i t}=g_{k} \ln w_{i t}, \ln y_{i t} ; \beta_{i}+v_{i t, k}, k=1, \ldots, K-1, \\
& i=1, \ldots, n, t=1, \ldots, T .
\end{aligned}
$$

using the same statistical assumptions as in (8). In this formulation, $\beta_{i}$ is a possible different vector for each DMU. We make the following assumption regarding $\beta_{i}$ :

$$
\beta_{i}=f_{\beta} \ln \tilde{w}_{i}, \ln \tilde{y}_{i}, \tilde{z}_{i}, i=1, \ldots, n,
$$

where $\ln \tilde{w}_{i}=T^{-1} \sum_{t=1}^{T} \ln w_{i t}, \ln \tilde{y}_{i}=T^{-1} \sum_{t=1}^{T} \ln \tilde{y}_{i t}$, are averages of log input prices and $\log$ outputs, respectively, and $\tilde{z}_{i} \in \mathbb{R}^{p_{z}}$ is an average vector of predetermined variables. Moreover, we choose $f_{\beta}$ to be a flexible functional form, viz. a translog form 
in our case. The system in (13) can be estimated to obtain $\hat{\beta}_{i}$ for all $i=1, \ldots, n$, estimates of technical inefficiency, etc.

When two DMUs are merged using (5), we have $n-1$ observations and the system in (13) can be re-estimated along with the vector $\alpha$ in (5), which is used to aggregate the inputs and outputs. This also of course affects (14) and the entire system in (13). This specification allows us to find the technology of the new firm easily as this will be described by one of the $\beta_{i} \mathrm{~s}$, which are re-estimated. Therefore, the question of how the technology of the new DMU changes can be addressed in a relatively straightforward manner.

\subsection{Statistical Inference}

The profit system in (9) is nonlinear in the parameters, but does not contain simultaneity. The system can be written in the general nonlinear seemingly unrelated regressions form:

$$
Y_{i t}=F\left(X_{i t} ; \beta_{\Pi, i}\right)+v_{i t}-u_{i t} \mathbf{1}
$$

where $Y_{i t}$ is the vector of left-hand-side variables in (9), $X_{i t}$ denotes log prices and $\log$ outputs, $\beta_{\Pi, i}$ is the DMU-specific technology parameter vector, $F()$ is a vector function, $v_{i t}$ has been defined in (12), $u_{i t}$ is profit inefficiency, and $\mathbf{1}=[1,0,0, \ldots, 0]^{\prime}$. For profit inefficiency, we adopt a general Cornwell, Schmidt and Sickles (1990, CSS) approach, viz:

$$
u_{i t}=\gamma_{i, 1}+\gamma_{i, 2} t+\frac{1}{2} \gamma_{i, 3} t^{2}
$$

Parameters $\gamma_{i, 1}, \gamma_{i, 2}, \gamma_{i, 3}$ are, from now on, assumed to be part of $\beta_{\Pi, i}$. Then technical inefficiency may be estimated as:

$$
\hat{u}_{i t}=\hat{\gamma}_{i, 1}+\hat{\gamma}_{i, 2} t+\frac{1}{2} \hat{\gamma}_{i, 3} t^{2}-\min _{i=1, \ldots, n ; t=1, \ldots, T} \hat{\gamma}_{i, 1}+\hat{\gamma}_{i, 2} t+\frac{1}{2} \hat{\gamma}_{i, 3} t^{2}, i=1, \ldots, n ; t=1, \ldots, T
$$

We follow a Bayesian approach to estimate (15) and (16). Denoting all parameters by $\theta$, our prior is:

$$
p(\theta) \propto \mathbb{I} \theta \in \Re
$$


where $\mathbb{I} \quad$ is the indicator function, and $\mathfrak{R}$ denotes the region of parameters where the profit function is non-increasing in $w$, and non-decreasing in $p$. Linear homogeneity is imposed in the profit function with respect to all input and output prices.

For the covariance matrix $\Sigma$ we assume the standard non-informative prior

$$
p(\Sigma) \propto|\Sigma|^{-(K+M+2) / 2} .
$$

Under the priors in (18) and (19), the posterior distribution is:

$$
p \theta, \Sigma|\mathbb{D} \propto L \theta, \Sigma| \mathbb{D} p \theta) p(\Sigma
$$

where $\mathbb{D}=[Y, X]$ is the data, and $L \theta, \Sigma \mid \mathbb{D}$ is the likelihood. After integrating analytically with respect to $\Sigma$, the posterior distribution is the following:

$$
\left.p \theta|\mathbb{D} \propto| \sum_{i=1}^{n} \sum_{t=1}^{T} v_{i t} \theta v_{i t} \theta^{\prime}\right|^{-n T / 2} \mathbb{I} \theta \in \mathfrak{R}
$$

where

$$
v_{i t} \theta \equiv Y_{i t}-F\left(X_{i t} ; \beta_{\Pi, i}\right)+u_{i t} \theta \mathbf{1},
$$

where $u_{i t} \theta$ is given by the CSS approach in (17).

As we mentioned before, we wish to place special priors on the parameters of vector $\alpha$ in (5). Our prior for $\alpha$ (a subset of $\theta$ ) is the following:

$$
\alpha \sim N_{K+M} \mu, h^{2} \mathbf{I}, \alpha \geq \mathbf{0}_{K+M},
$$

where $\mu=[1,1, \ldots, 1]^{\prime}$ and the scale parameter is $h=10$. This prior indicates that the weights are a priori likely to be close to one and with prior probability $95 \%$ they are in the interval from 0.31 to 22.5 . We consider this range particularly reasonable and most likely the prior will be easily reached by the data. Given (23), we have to modify (21) as follows:

$$
\left.p \theta|\mathbb{D} \propto| \sum_{i=1}^{n} \sum_{t=1}^{T} v_{i t} \theta v_{i t} \theta^{\prime}\right|^{-n T / 2} \mathbb{I} \theta \in \mathfrak{R} p \alpha
$$


Notice that for each element of $\alpha$, the prior is:

$$
p \quad \alpha_{j}=2 \pi h^{2} \mathrm{e}^{-1 / 2} \mathrm{e}^{-\left(\alpha_{j}-1\right)^{2} / 2 h^{2}}, j=1, \ldots, K+M
$$

We use the Girolami and Calderhead (2011) Riemannian manifold Hamiltonian Markov Chain Monte Carlo (MCMC) approach to explore the posterior in (24). We use 250,000 iterations the first 50,000 of which are discarded to mitigate possible start-up effects, and we monitor convergence and autocorrelation of MCMC carefully. ${ }^{6}$ Readers should note that Markov chain Monte Carlo (MCMC) methods are an alternative to noniterative methods for complex problems. The idea is to obtain a posterior sampling distribution and calculate sampling estimates characteristic of this distribution. The difference is that in this paper, we use iterative simulation techniques based on Markov chains; therefore, the values generated are no longer independent.

\section{Analysis and Discussion of Results}

Data on 196 Chinese banks for the 14-year period encompassed by 2002-2015 were obtained from the BvD-Bank Scope and annual reports of different banks in China. It covers most Chinese banks and excludes several banks that the data is missing. Our outputs are gross loans net of mortgage loans and residential mortgage loans. Our inputs are capital, labor, and deposits. Similarly to previous recent papers on potential M\&A in the banking industry, a production approach is adopted here (Wanke et al., 2016 and 2017). Specifically, under this approach, capital, labor, and deposits are employed by the financial institution to generate loans. We include number of branches and log total assets as quasifixed inputs in the profit function. The economic definition gives the level of mortgage loans which should be produced given the input prices and levels of fixed and quasi-fixed factors of production and output corresponding to the tangency of the short- and long-run average cost curves. For practical modelling purposes, we are assuming that the number of branches and assets may substantially vary in the long-run, although in the short term a given bank is committed to its production level. The descriptive statistics of the original data used in this research is presented in Table 1. As regards the business-related,

\footnotetext{
${ }^{6}$ Further details are available on request. We have found that a smaller number of MCMC iterations yield the same results. For example, 40,000 with a burn-in phase of 10,000 yields approximately the same result. This is direct evidence that our MCMC works quite well in practice. Convergence was monitored using the Geweke (1992) diagnostics. Autocorrelations of MCMC draws were never over 0.40, indicating good mixing and therefore thorough exploration of the posterior.
} 
contextual variables, adopted in this research, their dummy specification (0-1) can be found in Table 1. Zhong - please explain what mean each one of the dummy variables. 
Table 1. Descriptive statistics

\begin{tabular}{|c|c|c|c|c|c|}
\hline Variables & Min & Max & Mean & SD & $\mathrm{CV}$ \\
\hline $\begin{array}{l}\text { Residential Mortgage Loans [Thousand USD] - } \\
\text { Output }\end{array}$ & 0.00 & 430905934.00 & 17826356.53 & 54728866.42 & 3.07 \\
\hline Gross Loans [Thousand USD] - Output & 2311.00 & 1838321719.00 & 53029613.20 & 193649028.35 & 3.65 \\
\hline Total Customer Deposits [Thousand USD] - Input & 3726.00 & 2542343754.00 & 79100740.25 & 285555800.18 & 3.61 \\
\hline Total Assets [Thousand USD] - Input & 29986.00 & 3421363161.00 & 105120576.86 & 369418152.10 & 3.51 \\
\hline $\begin{array}{l}\text { Number of Employees - Quasi-fixed Input and } \\
\text { Denominator of Price of Labor (PL) }\end{array}$ & 57.00 & 503082.00 & 42777.36 & 106894.18 & 2.50 \\
\hline $\begin{array}{l}\text { Number of Branches - Quasi-fixed Input and } \\
\text { Denominator of Price of Capital (PK) }\end{array}$ & 1.00 & 24452.00 & 1586.74 & 4725.51 & 2.98 \\
\hline $\begin{array}{l}\text { Personnel Expenses [Thousand USD] - } \\
\text { Numerator of Price of Labor (PL) }\end{array}$ & 0.00 & 18307240.00 & 838574.08 & 2520021.27 & 3.01 \\
\hline $\begin{array}{l}\text { Fixed Assets [Thousand USD] - Numerator of } \\
\text { Price of Capital (PK) }\end{array}$ & 127.00 & 34572285.00 & 932895.54 & 3597377.53 & 3.86 \\
\hline $\begin{array}{l}\text { Impaired Loans ratio [\%] - Price for Residential } \\
\text { Mortgage Loans }\end{array}$ & 0.00 & 79.89 & 2.07 & 4.77 & 2.31 \\
\hline Real interest rate [\%] - Price for Gross Loans & -2.33 & 5.45 & 1.91 & 2.62 & 1.37 \\
\hline $\begin{array}{l}\text { Central Bank interest rate [\%] - Price for Total } \\
\text { Customer Deposits }\end{array}$ & 0.35 & 0.76 & 0.55 & 0.18 & 0.33 \\
\hline $\begin{array}{l}\text { Return On Avg Assets [\%] - Price for Total } \\
\text { Assets }\end{array}$ & -6.53 & 26.16 & 1.09 & 1.70 & 1.57 \\
\hline \multirow{2}{*}{ Big Banks } & \multicolumn{2}{|c|}{ Yes (1) } & \multicolumn{3}{|c|}{ No $(0)$} \\
\hline & \multicolumn{2}{|c|}{$7.65 \%$} & \multicolumn{3}{|c|}{$92.35 \%$} \\
\hline \multirow{2}{*}{ Listed Banks } & \multicolumn{2}{|c|}{ Listed (1) } & \multicolumn{3}{|c|}{ Not Listed (0) } \\
\hline & \multicolumn{2}{|c|}{$16.33 \%$} & \multicolumn{3}{|c|}{$83.67 \%$} \\
\hline \multirow{2}{*}{ State-Owned Banks } & \multicolumn{2}{|c|}{ State-Owned (1) } & \multicolumn{3}{|c|}{ Private $(0)$} \\
\hline & \multicolumn{2}{|c|}{$3.06 \%$} & \multicolumn{3}{|c|}{$96.94 \%$} \\
\hline \multirow{2}{*}{ Foreign Bank } & \multicolumn{2}{|c|}{ Foreign (1) } & \multicolumn{3}{|c|}{ Local (0) } \\
\hline & \multicolumn{2}{|c|}{$19.39 \%$} & \multicolumn{3}{|c|}{$80.61 \%$} \\
\hline \multirow{2}{*}{ Financial Crisis } & \multicolumn{2}{|c|}{ After Crisis (1) } & \multicolumn{3}{|c|}{ Before Crisis $(0)$} \\
\hline & \multicolumn{2}{|c|}{$57.14 \%$} & \multicolumn{3}{|c|}{$42.86 \%$} \\
\hline \multirow{2}{*}{ Internet Finance Development } & \multicolumn{2}{|c|}{ After Development (1) } & \multicolumn{3}{|c|}{ Before Development $(0)$} \\
\hline & \multicolumn{2}{|c|}{$21.43 \%$} & \multicolumn{3}{|c|}{$78.57 \%$} \\
\hline \multirow{2}{*}{ Loan Interest Rate Liberalization } & \multicolumn{2}{|c|}{ After Liberalization (1) } & \multicolumn{3}{|c|}{ Before Liberalization $(0)$} \\
\hline & & $1.43 \%$ & & $78.57 \%$ & \\
\hline
\end{tabular}

\subsection{Exploring possible mergers}

After MCMC we wish to examine mergers between different pairs of banks that improve: i) technical change, ii) efficiency, and iii) profits. The pairs of banks we examine are banks above median efficiency with banks below median efficiency. MCMC is reimplemented for each pair we wish to merge, and the results are recorded in terms of criteria 
in (i), (ii), and (iii). This is a highly computationally intensive experiment, but it is worth doing in order to evaluate whether mergers will increase technical change, efficiency, and/or profits in the Chinese banking system. With $n$ banks, as in our case, the number of

all possible different pairs is $\frac{n(n-1)}{2}$, so if $n=196$, as in our case, we would have 19,110 . As we considered efficient banks to be bought those banks below median efficiency, the pairs are reduced to 9,555, which is, of course, very computationally demanding. However, we do not apply any shortcuts to implement the MCMC, such as importance re-weighting (Rubin, 1987), to approximate the new posteriors arising from merging two banks and thus changing the sample. The reason we do not apply shortcuts is that we wish to provide accurate estimates of mergers, of course, but at the same time provide precise estimates of the weights $\alpha$ in (5). However, when implementing MCMC we have very good initial conditions and the number of iterations can be drastically reduced. ${ }^{7}$

\subsection{Results on merger evaluation}

As we have to examine 9,555 cases, we have to report only summary statistics ${ }^{8}$. The parameter estimates for the overall impact of several variables on the profit function of Chinese banks is given in Table 2. Readers should note that w1, w2, and w3 are $\log$ prices of capital, labor, and deposits. We use w3 to impose linear homogeneity of the profit function. Log prices of general loans and real estate loans are p1 and p2. NBR is number of branches, LTA is log total assets, and t is time trend. Bank-specific dummies are included. The weights $\alpha$ in (5) are not reported due to their large number. Productivity growth is computed as the sum of efficiency change and technical change. Although the use of Bayesian estimators does not allow to address the results in terms of "significance", higher ratios between posterior mean and s.d. (i.e. above 2 in modulus) suggest a strong impact of the variable on the production function.

Broadly speaking, the profit function of the Chinese banking industry is more impacted by capital than labor, and it seems to be modestly increasing over the course of the years analyzed. This result may be explained by the scarce opportunities that still exist for banking automation and for other electronic initiatives to support customer relationship management in China. General loans are more important than real estate loans for

\footnotetext{
${ }^{7}$ Given footnote 1, which is MCMC implemented for the first 100 pairs, we use the averages of posterior means as initial conditions. Then it is found that 5,000 iterations without discarding anything is quite adequate. Convergence was monitored using the Geweke (1992) diagnostics. Autocorrelations of MCMC draws were never over 0.40 , indicating good mixing and, therefore, thorough exploration of the posteriors. Therefore, even though we have to examine 9,555 merger cases, the drastic reduction in MCMC iterations make this exercise quite feasible in practice. On a high-performance computer using fortran 77 with 2,000 cores, computational time was about 10 minutes. For details of our computational environment, see http://www.lancaster.ac.uk/iss/services/hec/
}

${ }^{8}$ Full results are available upon request. 
generating profits, thus serving as a natural risk-mitigation portfolio strategy in case of an eventual crash due to another "housing bubble". Although average technical efficiency levels appear to be high, around 0.85 , technical change is higher than productive growth in Chinese banks, thus suggesting that the overall frontier is shifting faster than the ability of average individual banks to catch up with it. This may imply in the existence of opportunities for M\&A with low-performers in the Chinese banking industry.

As regards the dummy variables, it is possible to shed some light on the strategic fit of M\&A in Chinese banks. For instance, they tend to produce a positive impact on the profit function when banks are big in size, foreign, listed on the stock markets, and active in developing internet banking solutions for their customers. These results may suggest the need of further deregulating the Chinese bank system to allow a greater presence of large foreign financial institutions in the control of local domestic banks. Besides, although financial crises have impacted negatively the profit function of the Chinese banks from different types, origins, and size, it is worth noting that corporate governance mechanisms imposed by listing on the stock markets, together with electronic platforms for banking, may be used to mitigate its effects since their posterior means present almost the same magnitude. In other words, it would be interesting for banks technologically prepared for electronic banking solutions and listed on the stock markets to acquire small obsolete banks.

Table 2. Parameter estimates from the profit function system in (13) and (24) without mergers.

NOTES:

\begin{tabular}{|l|l|l|}
\hline & posterior mean & posterior s.d. \\
\hline $\mathrm{w}_{1}$ & -0.251 & 0.017 \\
\hline $\mathrm{w}_{2}$ & -0.172 & 0.023 \\
\hline $\mathrm{p}_{1}$ & 0.335 & 0.031 \\
\hline $\mathrm{p}_{2}$ & 0.221 & 0.018 \\
\hline NBR & 0.019 & 0.007 \\
\hline LTA & 0.033 & 0.008 \\
\hline $\mathrm{t}$ & 0.012 & 0.005 \\
\hline $\mathrm{w}_{1}{ }^{2}$ & 0.027 & 0.004 \\
\hline $\mathrm{w}_{1}{ }^{*} \mathrm{w}_{2}$ & 0.014 & 0.003 \\
\hline $\mathrm{w}_{1}{ }^{*} \mathrm{p}_{1}$ & 0.107 & 0.002 \\
\hline & & 18 \\
\hline
\end{tabular}




\begin{tabular}{|c|c|c|}
\hline $\mathrm{w}_{1} * \mathrm{p}_{2}$ & -0.091 & 0.044 \\
\hline w1*NBR & 0.212 & 0.032 \\
\hline w1*LTA & 0.332 & 0.015 \\
\hline $\mathrm{w}_{1} * \mathrm{t}$ & -0.014 & 0.003 \\
\hline $\mathrm{w}_{2}^{2}$ & 0.133 & 0.019 \\
\hline $\mathrm{w}_{2} * \mathrm{p}_{1}$ & 0.135 & 0.031 \\
\hline $\mathrm{w}_{2} * \mathrm{p}_{2}$ & -0.142 & 0.025 \\
\hline $\mathrm{w}_{2} * \mathrm{NBR}$ & 0.105 & 0.028 \\
\hline $\mathrm{w}_{2}{ }^{*} \mathrm{LTA}$ & 0.133 & 0.033 \\
\hline $\mathrm{w}_{2} * \mathrm{t}$ & -0.004 & 0.001 \\
\hline $\mathrm{p}_{1}^{2}$ & 0.144 & 0.031 \\
\hline $\mathrm{p}_{1} * \mathrm{p}_{2}$ & 0.072 & 0.015 \\
\hline $\mathrm{p}_{1} * \mathrm{NBR}$ & 0.144 & 0.006 \\
\hline $\mathrm{p}_{1}$ *LTA & 0.232 & 0.003 \\
\hline $\mathrm{p}_{1} * \mathrm{t}$ & -0.011 & 0.003 \\
\hline $\mathrm{p}_{2}^{2}$ & 0.051 & 0.014 \\
\hline $\mathrm{p}_{2} * \mathrm{NBR}$ & 0.155 & 0.007 \\
\hline $\mathrm{p}_{2} *$ LTA & 0.108 & 0.005 \\
\hline $\mathrm{p}_{2} * \mathrm{t}$ & 0.033 & 0.006 \\
\hline $\mathrm{NBR}^{2}$ & 0.018 & 0.004 \\
\hline NBR*LTA & 0.044 & 0.011 \\
\hline NBR*t & 0.030 & 0.006 \\
\hline $\mathrm{LTA}^{2}$ & 0.125 & 0.003 \\
\hline LTA* $^{*}$ & 0.017 & 0.006 \\
\hline$\overline{t^{2}}$ & -0.015 & 0.002 \\
\hline Dummy, big bank & 0.077 & 0.015 \\
\hline Dummy, listed bank & 0.041 & 0.005 \\
\hline Dummy, foreign bank & 0.052 & 0.007 \\
\hline Dummy, financial crisis & -0.082 & 0.004 \\
\hline Dummy, internet finance development & 0.033 & 0.003 \\
\hline inefficiency & 0.151 & 0.042 \\
\hline technical change & 0.032 & 0.017 \\
\hline
\end{tabular}




\begin{tabular}{|l|l|l|}
\hline productivity growth & 0.021 & 0.009 \\
\hline
\end{tabular}

The results for the M\&A assessment are presented in Table 3. Readers should note that TC is technical change, EFF is efficiency, and PR is productivity growth. Posterior standard deviations appear in parentheses. It is interesting to note that since the average technical efficiency levels of the Chinese banking industry are relatively high (about 0.85), most mergers (about $35.33 \%$ of the cases) will produce beneficial effects on the frontier shift and catch-up components of the stochastic profit function. As a matter of fact, the risks of technological regression in the Chinese banking industry due to M\&A appears to be minimal since most mergers not only yield higher technical change levels (in $72.37 \%$ of cases), but also because technical change is a component of the stochastic profit function always present in different sample cuts. On the other hand, however, the risks of deepening the weakness of the catch-up component towards the profit function are not negligible. In only $37.35 \%$ of the M\&A cases analyzed an increase in productivity change was verified, which is quite a low percentage when compared to the cases where higher technical change and technical efficiency improved. Again, these results suggest that there is room left for reviewing the regulation of the Chinese banking system not only in terms of its opening to foreign capital, but also in terms of additional measures that could be addressed to improve the overall productivity of the system. Table 4 may suggest additional insights on this subject.

\section{Table 3. Merger evaluation}

\begin{tabular}{|l|l|l|}
\hline$\%$ mergers yielding higher TC & & Average improvement \\
\hline$\%$ mergers yielding higher EFF & $72.37 \%$ & $3.17 \%(0.15 \%)$ \\
\hline$\%$ mergers yielding higher PR & $63.51 \%$ & $7.22 \%(1.35 \%)$ \\
\hline$\%$ mergers yielding higher TC, EFF \& PR & $37.25 \%$ & $3.45 \%(0.32 \%)$ \\
\hline$\%$ mergers yielding higher TC \& EFF & $29.44 \%$ & $2.52 \%(0.33 \%)$ in TC \\
& $5.13 \%(0.47 \%)$ in EFF \\
\hline mergers yielding higher TC \& PR & $32.32 \%$ & $1.49 \%(0.43 \%)$ in TC \\
\hline
\end{tabular}




\begin{tabular}{|l|l|l|}
\hline$\%$ mergers yielding higher TC \& EFF & $30.44 \%$ & $0.44 \%(0.12 \%)$ in TC \\
& & $4.81 \%(0.21 \%)$ in EFF \\
\hline
\end{tabular}

Table 4 reports the variations in the individual input/output components of the profit function due to M\&A. Readers should recall that values of alpha equal to one indicate that the sum of individual inputs/outputs before and after the M\&A process do not vary and, therefore, there are no synergistic consequences from it. Due to the large number of weights $\alpha$ in (5), we will present their sample descriptive statistics of posterior means obtained by applying our MCMC procedure. These posterior means are robust to parameter statistical uncertainty since we use the Bayesian approach. There are five elements in total: three inputs and two outputs.

As readers may note, outputs increase proportionally more than the inputs, thus broadly suggesting a strong synergistic effect in merging Chinese banks. It is worth noting, however, that this synergistic effect in labor is almost negligible. Hence, this result suggests that there is no room left for employee downsizing or personnel cut. Productivity gains in the Chinese banking system should be obtained from the exploitation of synergistic effects in capital (total assets, branches, etc.) and deposits. Precisely as regards to capital, merged banks should not only pay attention to opportunities in redesigning their network of branches, possibly closing redundant ones, but also on the compositing of the resulting assets, exploring opportunities for reviewing write-offs and getting rid of deprecated rights. On the other hand, as regards to deposits, there seems to be room left for developing new loan products or alternative financial products.

Table 4 Sample statistics for posterior means of weights $\alpha$ in (5).

\begin{tabular}{|l|l|l|l|}
\hline & mean & s.d. & $95 \%$ HPDI \\
\hline capital & 1.841 & 0.032 & $1.62-1.988$ \\
\hline labor & 1.012 & 0.007 & $0.998-1.019$ \\
\hline deposits & 1.317 & 0.018 & $1.25-1.42$ \\
\hline general loans & 3.122 & 0.125 & $2.74-3.61$ \\
\hline real estate loans & & & \\
\hline
\end{tabular}


NOTES: HDPI is highest posterior density interval and it is approximated numerically using our MCMC draws. 
At last, as a register for readers, Figures 1, 2, and 3 present the distributions for technical inefficiency, technical change, and productivity change/growth without and with a given number of M\&As.

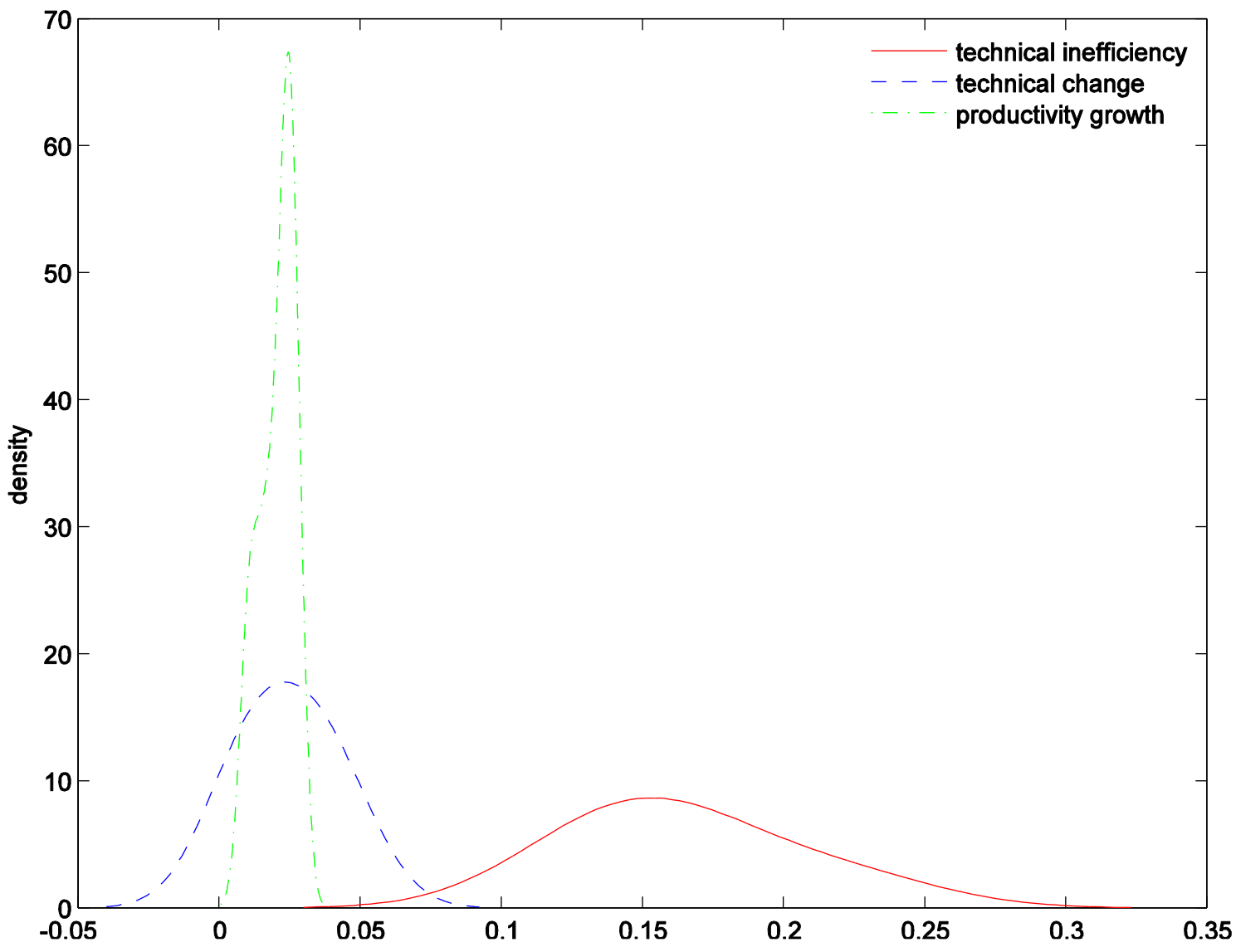

Fig. 1: Technical Inefficiency, Technical Change, and Productivity Growth in the original sample. 


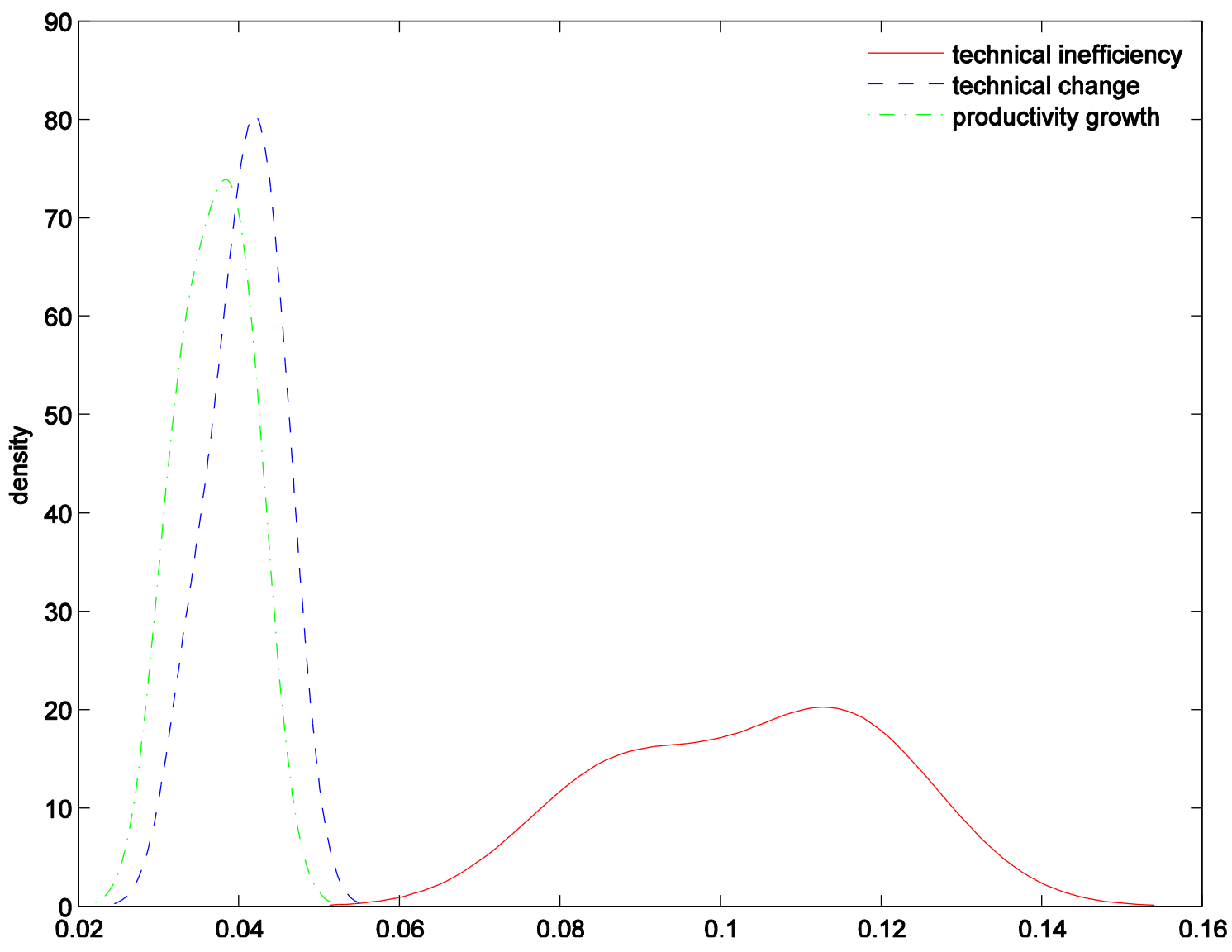

Fig. 2: Technical Inefficiency, Technical Change, and Productivity Growth after 100 random mergers 


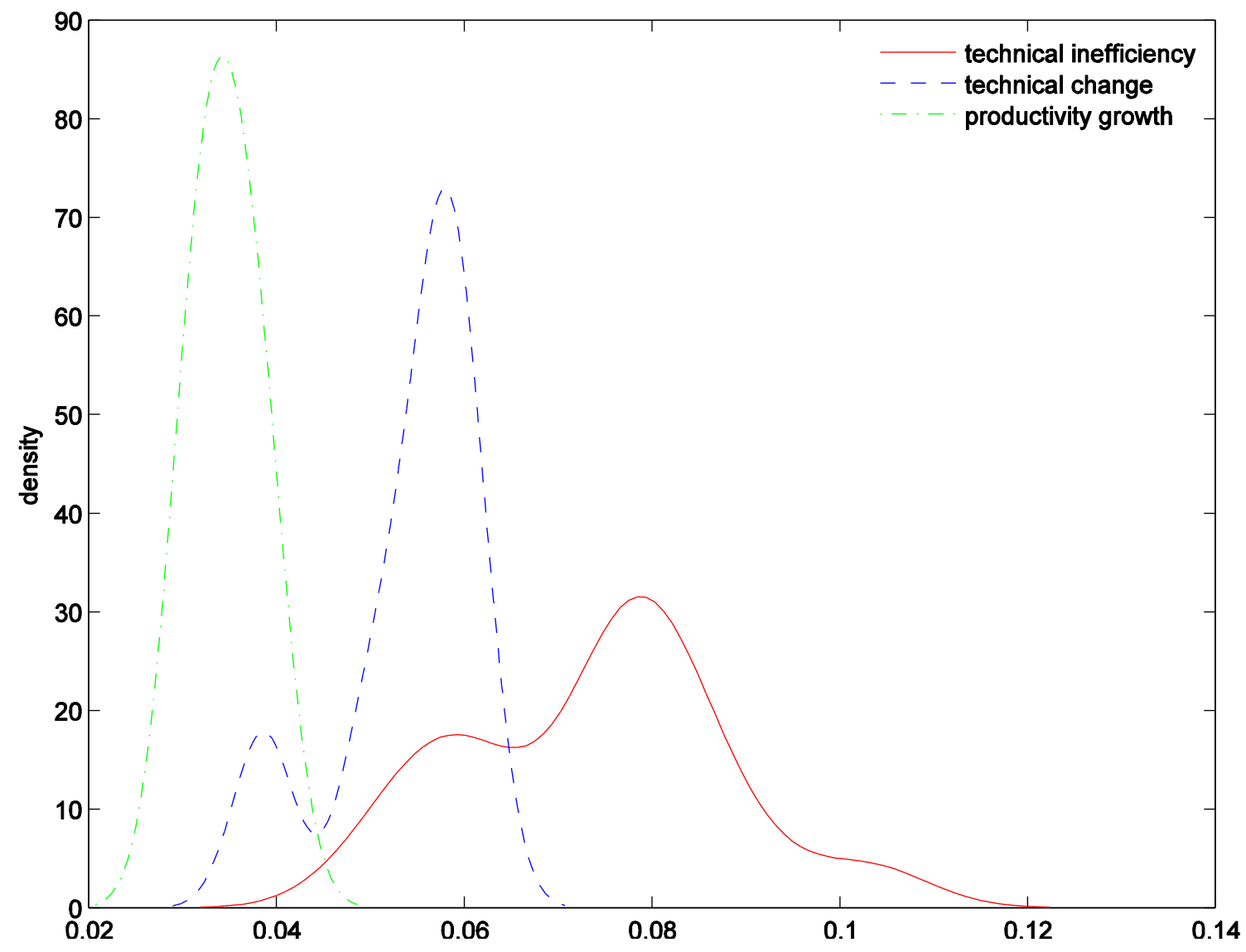

Fig. 3: Technical Inefficiency, Technical Change, and Productivity Growth after 1,000 random mergers 


\section{Conclusions}

This paper presents an analysis of the efficiency of Chinese banks using a novel SFA model for handling M\&As. This approach enables the technical efficiency of a potentially merged bank to be assessed not only in overall terms, but also with respect to the technical change and productivity change in light of several dummy variables related to size, origin, and other features of the banks. It thus makes it possible to derive prospective scenarios for merging in the Chinese banking industry and to propose policies and measures for this sector.

According to the research, we find that the profit function of the Chinese banking industry is more impacted by capital than labor, while general loans are more important than real estate loans for generating profits. On average, the technical efficiency levels of Chinese banks appear to be as high as 0.85 , while the technical change is higher than productive growth, implying the overall frontier is shifting faster than the ability of the average individual banks to catch up with it.

Moreover, some contextual variables also play a very important role on the management of Chinese banks. For instance, they tend to produce a positive impact on the profit function when banks are big in size, foreign, listed on the stock markets, and active in developing internet banking solutions for their customers, while the global financial crisis has impacted negatively the profit function of the Chinese banks. These results are also consistent with some previous research. These results show the direction for the future reform and M\&As.

At last, the results for the M\&A assessment show that there is room or opportunity left for future M\&A activities in the Chinese banking industry. However, this synergistic effect in labor is almost negligible, while synergistic effects in capital (total assets, branches, etc.) and deposits are more significant, indicating that the priority of M\&As should be put on the allocation of assets. Putting it into other words, efficiency gains to be exploited from M\&A in Chinese banking are mostly due fixed asset rationalization, rather than labor reorganization, what calls for further automation in financial practices and in customer relationships.

Most existing M\&As were made by the foreign financial companies in the banking sector of China. At present, the Chinese banks are going through a stage of rapid development. The reform experienced had indeed brought out this success, which is also supported by the empirical results mentioned above. Meanwhile, our research also shows the feasibility and the direction for more M\&As in the Chinese banks industry. This is the first paper that focuses on the M\&As of Chinese banks and that analyzes the potential benefits of future M\&As in different situations with SFA models. This will help the 
government authorities as well as the manager of commercial banks to make decisions in the M\&A activities. Further research is still needed to confirm the present outcomes.

\section{References}

Alba, J. D., Park, D., \& Wang, P. (2009). Corporate governance and merger and acquisition (M\&amp;A) FDI: Firm-level evidence from Japanese FDI into the US. Journal of Multinational Financial Management, 19(1), 1-11.

Amel, D., Barnes, C., Panetta, F., \& Salleo, C. (2004). Consolidation and efficiency in the financial sector: A review of the international evidence. Journal of Banking \& Finance, 28(10), 2493-2519.

Barros, C. P., Chen, Z., Liang, Q. B., \& Peypoch, N. (2011). Technical efficiency in the Chinese banking sector. Economic Modelling, 28(5), 2083-2089.

Baten, M. A., \& Kamil, A. A. (2011). A stochastic frontier model for measuring online bank profit efficiency. South African Journal of Business Management, 42(3), 4959.

Beccalli, E., \& Frantz, P. (2009). M\&A operations and performance in banking. Journal of Financial Services Research, 36(2-3), 203.

Berger, A. N., Hasan, I., \& Zhou, M. (2009). Bank ownership and efficiency in China: What will happen in the world's largest nation? Journal of Banking \& Finance, 33(1), 113-130.

Bogetoft, P., \& Wang, D. (2005). Estimating the potential gains from mergers. Journal of Productivity Analysis, 23(2), 145-171.

Chaffai, M. (1998). Estimation des inefficiencies techniques et allocatives des banques de depots tunisiennes: une frontière de coût fictive. Économie \& Prévision, 136(5), 117-119.

Chaffai, M. \& Dietsch, M. (1999). Mesures de l'efficience technique et de l'efficience allocative par les fonctions de distance et application aux banques européennes. Revue économique, 633-644.

Chaffai, M., \& Dietsch, M. (2000). Comment accroitre les performances des banques tunisienne: une question d'organisation ou de taille. Finances \& Développement au Maghreb, 24, 79-89. 
Chapin, A., \& Schmidt, S. (1999). Do mergers improve efficiency? Evidence from deregulated rail freight. Journal of Transport Economics and Policy, 33(2), 147162.

Chow, C. K.W., \& Fung, M. K. Y. (2012). Measuring the effects of China's airline mergers on the productivity of state-owned carriers. Journal of Air Transport Management, $25,1-4$.

Cornwell, C., Schmidt, P., \& Sickles, R. C. (1990). Production Frontiers with Crosssectional and Time-series Variation in Efficiency Levels. Journal of Econometrics, 46,185-200.

Craig, B. R., \& Dinger, V. (2009). Bank mergers and the dynamics of deposit interest rates. Journal of Financial Services Research, 36(2-3), 111.

DeLong, G., \& DeYoung, R. (2007). Learning by observing: Information spillovers in the execution and valuation of commercial bank M\&As. The Journal of Finance, 62(1), $181-216$.

Dietsch, M. (1992). Quel modèle de concurrence dans l'industrie bancaire? Revue Économique, 43(2), 229-260.

Dietrich, J.K., \& Sorensen, E. (1984). An Application of logit analysis to prediction of merger targets. Journal of Business Research, 12(3), 393-402.

Dong, Y., Hamilton, R., \& Tippett, M. (2014). Cost efficiency of the Chinese banking sector: A comparison of stochastic frontier analysis and data envelopment analysis. Economic Modelling, 36, 298-308.

Du, K., \& Sim, N. (2016). Mergers, acquisitions, and bank efficiency: Cross-country evidence from emerging markets. Research in International Business and Finance, $36,499-510$.

Fernández-Arias, D., López-Martín, M., Montero-Romero, T., Martínez-Estudillo, F., \& Fernández-Navarro, F. (2017). Financial Soundness Prediction Using a Multiclassification Model: Evidence from Current Financial Crisis in OECD Banks. Computational Economics, 1-23.

Fried, H.O., Lovell, C.A., \& Yaisawarng, S. (1999). The impact of mergers on credit union service provision. Journal of Banking \& Finance, 23(2/4), 367-386.

Fu, Xiaoqing Maggie, \& Heffernan, S. (2007). Cost X-efficiency in China's banking sector. China Economic Review, 18(1), 35-53. 
Fungáčová, Z., Pessarossi, P., \& Weill, L. (2013). Is bank competition detrimental to efficiency? Evidence from China. China Economic Review, 27, 121-134.

Gale, D., \& Shapley, L.S. (1962). College admissions and the stability of marriage. The American Mathematical Monthly, 69(1), 9-15.

Gattoufi, S., Amin, G. R., \& Emrouznejad, A. (2014). A new inverse DEA method for merging banks. IMA Journal of Management Mathematics, 25(1), 73-87. doi:10.1093/imaman/dps027

Geweke, J. (1992). Evaluating the Accuracy of Sampling-Based Approaches to the Calculation of Posterior Moments. In J. M. Bernardo, J. Berger, A. P. Dawid, \& A. F.M. Smith (Eds.), Bayesian Statistics (pp. 169-193). Oxford: Oxford University Press.

Ghosh, A., 2001. Does operating performance really improve during corporate acquisitions? J. Corporate Finance, 7(2), 151-178.

Girolami, M., \& Calderhead, B. (2011). Riemann manifold Langevin and Hamiltonian Monte Carlo methods. Journal of the Royal Statistical Society: Series B, 73(2), 123214.

Halkos, G.E., \& Tzeremes, N.G. (2013). Estimating the degree of operating efficiency gains from a potential bank merger and acquisition: A DEA bootstrapped approach. Journal of Banking \& Finance, 37(5), 1658-1668.

Harris, J., Ozgen, H., \& Ozcan, Y. (2000). Do mergers enhance the performance of hospital efficiency? The Journal of the Operational Research Society, 51(7), 801-811.

Hsiao, C., Shen, Yan \& Bian, Wenlong. (2015). Evaluating the effectiveness of China's financial reform-The efficiency of China's domestic banks. China Economic Review, 35, 70-82.

Ho, S.J., and Mallick, S.K. (2010), The impact of information technology on the banking industry, Journal of the Operational Research Society, 61 (2): 211-221.

Jiang, C., Yao, S., \& Zhang, Z. (2009). The effects of governance changes on bank efficiency in China: A stochastic distance function approach. China Economic Review, 20(4), 717-731.

Johnes, J., \& Yu, L. (2008). Measuring the research performance of Chinese higher education institutions using data envelopment analysis. China Economic Review, 19(4), 679-696. 
Kohers, T., Huang, M. H., \& Kohers, N. (2000). Market perception of efficiency in bank holding company mergers: the roles of the DEA and SFA models in capturing merger potential. Review of Financial Economics, 9(2), 101-120.

Kraft, E., \& Tirtıroğlu, D. (1998). Bank efficiency in Croatia: A stochastic-frontier analysis. Journal of Comparative Economics, 26(2), 282-300.

Liu, H. H., Chen T.Y., \& Pai, L.Y. (2007). The influence of merger and acquisition activities on corporate performance in the Taiwanese telecommunications industry. The Service Industries Journal, 27(8), 1041-1051.

Lo, F.Y., Chien, C.F., \& Lin, J. T. (2001). A DEA study to evaluate the relative efficiency and investigate the district reorganization of the Taiwan power company. IEEE Transactions on Power Systems, 21(2), 55-56.

Lozano, S., \& Villa, G. (2010). DEA-based pre-merger planning tool. Journal of the Operational Research Society, 61(10), 1485-1497.

Mamatzakis, E., Matousek, R., \& Vu, A. N. (2015). What is the impact of bankrupt and restructured loans on Japanese bank efficiency?. Journal of Banking \& Finance, 72, S187-S202.

Manson, S., Powell, R., Stark, A. W., Thomas, H. M., 2000. Identifying the sources of gains from takeovers. Account. Forum 24(4), 319-343.

Okeahalam, C. C. (2006). Production efficiency in the South African banking sector: A stochastic analysis. International Review of Applied Economics, 20(1), 103-123.

Pasiouras, F., \& Gaganis, C. (2007). Financial characteristics of banks involved in acquisitions: evidence from Asia. Applied Financial Economics, 17(4), 329-341.

Pessarossi, P., \& Weill, L. (2015). Do capital requirements affect cost efficiency? Evidence from China. Journal of Financial Stability, 19, 119-127.

Peyrache, A. (2013). Industry structural inefficiency and potential gains from mergers and break-ups: A comprehensive approach. European Journal of Operational Research, 230(2), 422-430.

Powell, R.G. (2001). Takeover prediction and portfolio performance: A note. Journal of Business Finance \& Accounting, 28(7/8), 993-1011.

Rahman, R. A., Limmack, R. J., 2004. Corporate acquisitions and the operating performance of Malaysian companies. J. Bus. Finance \& Account. 31(3/4), 359400. 
Rubin, D. B. (1987). The calculation of posterior distributions by data augmentation: Comment: A noniterative sampling/importance resampling alternative to the data augmentation algorithm for creating a few imputations when fractions of missing information are modest: The SIR algorithm. Journal of the American Statistical Association, 82(398), 543-546.

Sassenou, M. (1992). Economies de coûts dans les banques et les caisses d'épargne, impact de la taille et de la variété de produits. Revue Économique, 43(2), 277-300.

Shi, X., Yongjun, L., Emrouznejad, A., Xie, J., \& Liang, L. (in press). Estimation of potential gains from bank mergers: A novel two-stage cost efficiency DEA model. Journal of the Operational Research Society. doi:10.1057/s41274-016-0106-2

Silva, P.P., Vieira, I., \& Vieira, C., (2015). M\&A operations: Further evidence of informed trading in the CDS market. Journal of Multinational Financial Management, 32/33, 116-130.

Silva, T. C., Tabak, B. M., Cajueiro, D. O., \& Dias, M. V. B. (2017). A comparison of DEA and SFA using micro-and macro-level perspectives: Efficiency of Chinese local banks. Physica A: Statistical Mechanics and its Applications, 469, 216-223.

Song, X. L., \& Chu, Y. H. (2006). A study on financial strategy for determining the target enterprise of merger and acquisition. Journal of Modern Accounting and Auditing, 2(4), 55-60.

Sudarsanam, S. (2010). Creating Value from Mergers and Acquisitions the Challenges, Second Edition, Pearson Education Limited, Edinburgh Gate, Harlow, Essex CM20 $2 \mathrm{JE}$, England.

Sun, L., \& Chang, T. P. (2011). A comprehensive analysis of the effects of risk measures on bank efficiency: Evidence from emerging Asian countries. Journal of Banking \& Finance, 35(7), 1727-1735.

Sun, J., Harimaya, K., \& Yamori, N. (2013). Regional economic development, strategic investors, and efficiency of Chinese city commercial banks. Journal of Banking \& Finance, 37(5), 1602-1611.

Tabak, B. M., Fazio, D. M., \& Cajueiro, D. O. (2013). Systemically important banks and financial stability: The case of Latin America. Journal of Banking \& Finance, 37(10), 3855-3866.

Toloo, M., Masoumzadeh, A., \& Barat, M. (2015). Finding an initial basic feasible solution for DEA models with an application on bank industry. Computational Economics, 45(2), 323-336. 
Wanke, Peter; BARROS, CARLOS P. ; AZAD, MD. ABUL KALAM ; CONSTANTINO, DERCIO . The Development of the Mozambican Banking Sector and Strategic Fit of Mergers and Acquisitions: A Two-Stage DEA Approach-. AFRICAN DEVELOPMENT REVIEW, v. 28, p. 444-461, 2016.

Wanke, Peter; MAREDZA, ANDREW ; GUPTA, RANGAN . Merger and acquisitions in South African banking: A network DEA model. RESEARCH IN INTERNATIONAL BUSINESS AND FINANCE, v. 41, p. 362-376, 2017.

Weber, J. A., \& Dholakia, U.M. (2000). Including marketing synergy in acquisition analysis: A step-wise approach. Industrial Marketing Management, 29(2), 157-177.

Yin, H., Yang, J., Mehran, J. (2013). An empirical study of bank efficiency in China after WTO accession. Global Finance Journal, 24(2), 153-170. 